Georgia State University

ScholarWorks @ Georgia State University

\title{
The Cognitive, Affective, and Somatic Empathy Scales (CASES): Cross-Cultural Replication and Specificity to Different Forms of Aggression and Victimization
}

\author{
Frances Chen \\ Georgia State University, rchen6@gsu.edu \\ Annis Lai Chu Fung \\ City University of Hong Kong, annis.fung@cityu.edu.hk \\ Adrian Raine \\ University of Pennsylvania, araine@sas.upenn.edu
}

Follow this and additional works at: https://scholarworks.gsu.edu/cj_facpub

Part of the Criminology and Criminal Justice Commons

\section{Recommended Citation}

Chen, Frances R., Annis Lai Chu Fung, and Adrian Raine. The Cognitive, Affective, and Somatic Empathy Scales (CASES): Cross-Cultural Replication and Specificity to Different Forms of Aggression and Victimization. Journal of Personality Assessment, DOI: 10.1080/00223891.2019.1677246

This Article is brought to you for free and open access by the Department of Criminal Justice and Criminology at ScholarWorks @ Georgia State University. It has been accepted for inclusion in CJC Publications by an authorized administrator of ScholarWorks @ Georgia State University. For more information, please contact scholarworks@gsu.edu. 
The Cognitive, Affective and Somatic Empathy Scales (CASES): Cross-Cultural Replication and Specificity to Different Forms of Aggression and Victimization

\begin{abstract}
A psychometrically sound measure of empathy that captures its multifaceted nature is critical in furthering research on empathy. The only instrument that assesses three domains of empathy together with positive and negative valence empathy is the newly developed 30 -item Cognitive Affective and Somatic Empathy Scales (CASES). The current study examines the cross-culture generalizability of CASES in Hong Kong and explores links between empathy and different forms of aggression and peer victimization. A sample of 4676 Hong Kong youth (62\% male) completed CASES, alongside measures of reactive/proactive aggression and multidimensional peer victimization. A subsample of youth $(n=2321-2464)$ and their parents completed additional instruments for testing the validity of CASES. We replicated most of the concurrent, convergent, and discriminant validity findings in the original development of CASES. Proactive aggression was most strongly linked to affective empathy, whereas reactive aggression was most strongly linked to somatic empathy. Differential associations were revealed between subscales of CASES and forms of peer victimization. Findings provide cross-cultural generalizability for a brief selfreport instrument that captures the multifaceted nature of empathy. The multifaceted nature of empathy is further supported by differential associations with forms of aggression and victimization.
\end{abstract}

Keywords: Empathy, CASES, Proactive Aggression, Reactive Aggression, Peer Victimization 
The Cognitive, Affective and Somatic Empathy Scales (CASES): Cross-Cultural Replication and Specificity to Different Forms of Aggression and Victimization

Empathy is broadly defined as the experience and understanding of what others feel in terms of emotion and sensory state. In the past decades, increasing research has been devoted to identifying the neural basis of empathy (see Bernhardt \& Singer, 2012 for a review), the role of empathy in aggression and psychopathy (Blair, 2018), and bullying (van Noorden, Haselager, Cillessen, \& Bukowski, 2015). The importance of empathy is further highlighted by the fact that empathy training is incorporated as a key element in school-based bullying prevention and intervention programs (Espelage, Mebane, \& Adams, 2004; Farrington \& Ttofi, 2009).

There is growing consensus that empathy is a multifaceted construct that includes cognitive, affective and motor domains (Blair, 2005; Clark, Robertson, \& Young, 2019; Van Der Graaff et al., 2016) and dissociable underlying neurocognitive systems for the domains have been revealed (Bernhardt \& Singer, 2012; Blair, 2005; Shamay-Tsoory, Aharon-Peretz, \& Perry, 2009). However, the exact definitions of the empathy domains are at least controversial. For example, there are debates over whether cognitive empathy can be considered "empathy" alone when there is no emotional component involved. Similarly, different opinions exist regarding whether affective empathy refers to feel as (feeling the emotion of others) or feel for the others (involving an empathic response) (Hein \& Singer, 2008) and whether empathy is necessarily associated with behavioral outcomes. These controversial issues have been examined and summarized in a recent review (Cuff, Brown, Taylor, \& Howat, 2016), and it reflects the current state of the literature. For this study, we employed the following definitions of the three domains of empathy. Specifically, cognitive empathy is the ability to represent the thoughts, beliefs, intentions, and knowledge of others (Austin, Bondü, \& Elsner, 2017; Sebastian et al., 2012). 
Affective empathy refers to emotional experience ("feel as") the display of others' emotions or emotional stimuli (Caravita, Di Blasio, \& Salmivalli, 2009; Vachon, Lynam, \& Johnson, 2014). Motor (somatic) empathy is the tendency to automatically mimic sensory output such as facial expression and movement of others (Blair, 2005; Raine \& Chen, 2018). Affective empathy and cognitive empathy have been assessed with various self-report instruments such as Interpersonal Reactivity Index (Davis, 1983), but motor/somatic empathy is typically assessed with laboratory physiological measures such as facial electromyography (EMG) (Van Der Graaff et al., 2016).

Moreover, prior research on empathy has typically focused on negative affect, despite a long-standing interest on positive affect in psychology research. Positive empathy is a relatively new topic, and it is suggested that positive empathy may be associated with prosocial behavior and social closeness (see Morelli, Lieberman, \& Zaki, 2015 for a review). A recent study also revealed that negative affect and positive affect in empathy are not equivalent (Van Der Graaff et al., 2016).

The only instrument that we know of that assesses all three domains and separates positive and negative valence of empathy is the recently developed Cognitive, Affective and Somatic Empathy Scales (CASES; Raine \& Chen, 2018). With its ease of implementation, such an instrument could be of significant use in large-scale longitudinal research that explores the development of empathy over the life-course. Additionally, its comprehensive assessment encompassing different domains and valences for empathy could facilitate the examination of the differential associations between the multifaceted empathy construct and a host of psychopathological outcomes along with intermediary mechanisms. It is proposed that the neglect of the multifaceted nature of empathy could partially explain the fact that bullying prevention and intervention programs with an empathy training component are not often as 
effective as designed (van Noorden et al., 2015). An instrument that allows better assessments of the multifaceted empathy construct would aid this endeavor. Last, a validated domain- and valence-specific empathy measure will facilitate the exploration of the link between empathic traits and physiological empathetic responses (e.g., Singer et al., 2004).

Consistent with prior efforts, an empathy instrument should be associated with related constructs such as callous-unemotional traits (Frick \& White, 2008; Pardini, Lochman, \& Powell, 2007), and behavioral outcomes including antisocial behavior (see Jolliffe \& Farrington, 2004 for a review). In addition, research has consistently revealed sex differences in empathy with females having higher empathy scores (Derntl et al., 2010; Raine \& Chen, 2018; Rueckert \& Naybar, 2008). Although empathy has been proposed as a "risky strength" for internalizing problems (Tone \& Tully, 2014), the few studies that have explored the direct link between empathy and anxiety-depression have found null results in youth (Batanova \& Loukas, 2011; Raine \& Chen, 2018). Building upon these prior findings, the current study tests the criterion and construct validity of scores on the CASES with callous-unemotional traits, antisocial behavior and anxiety/depression in a Hong Kong youth sample.

The relationship between empathy and aggression is, in contrast less consistent, with one meta-analysis study revealing only a small and weak negative effect (Vachon et al., 2014). It is argued that reduced empathy may play a more important role in proactive aggression compared to reactive aggression (Blair, 2018), and the weak or null relations between empathy and aggression could stem from conflating the two functions of aggression in research (Raine \& Chen, 2018). Proactive aggression is characterized as callous and goal-directed aggression and is driven by gaining rewards, profits, and dominance (Dodge \& Coie, 1987; Raine et al., 2006). Reactive aggression is, in contrast, emotionally charged, impulsive, and accompanied by 
negative emotions such as frustration and anger (Dodge \& Coie, 1987; Raine et al., 2006). Developmentally, proactively aggressive children are more likely to have conduct disorder, delinquency, and disruptive behavior (Atkins \& Stoff, 1993; Vitaro, Gendreau, Tremblay, \& Oligny, 1998). Children exhibiting more reactive aggression tend to develop more internalizing problems such as depression and anxiety (Fite et al., 2010; Raine et al., 2006; Vitaro, Brendgen, \& Tremblay, 2002). Blair (2018) articulated dissociable neurocognitive bases for three different empathic mechanistic processes, including the lack or reduced inhibition of aggression in response to distress cues, the impaired associative learning of aggression with other's distress, and the abnormally utilitarian-oriented moral judgment. He proposed that when these empathic mechanistic processes were compromised, youth are at higher risk for proactive aggression rather than reactive aggression. Consistent with this proposition, studies have revealed a negative association between proactive aggression and empathy (Raine \& Chen, 2018), and between proactive aggression and warmth/concern for feelings (Fung, Gerstein, Chan, \& Engebretson, 2015). One recent study (Austin et al., 2017), however, provided contradictory evidence, finding that empathy was negatively associated with not only proactive aggression but also reactive aggression a year later. This difference could stem from the different developmental stages in that the first two studies (Fung et al., 2015; Raine \& Chen, 2018) which included youth that were over 9 years, whereas Austin and colleagues's study (2017) focused only on 6- to 9-year-olds where school entry may have placed higher demands on younger children.

A systematic review of empathy and bullying has shown that bullying, victimization, defending, and bystanding are uniquely linked to cognitive and affective empathy (van Noorden et al., 2015). Despite the abundant research on empathy and bullying (e.g., Caravita et al., 2009; Endresen \& Olweus, 2001; Gini, Albiero, Benelli, \& Altoè, 2007), few have explored the 
association between various aspects of peer victimization (e.g., physical victimization, social manipulation) and differentiating multiple dimensions of empathy, and even fewer have focused on late childhood and adolescence. Caravita, Di Blasio, and Salmivalli (2010) found that affective but not cognitive empathy was positively correlated with victimization in early adolescence. In contrast, Kokkinos and Kipritsi (2012) showed that both affective and cognitive empathy were negatively associated with victimization in preadolescence. Nevertheless, when victimization was broken down into direct (physical and verbal) versus indirect (social exclusion) victimization, they found that cognitive empathy was negatively associated with indirect but not direct victimization, whereas affective empathy was positively associated with direct but not indirect victimization. Additionally, Espelage et al. (2004) found that victims displayed more empathy and caring behavior than bullies. As such, findings overall are mixed and call for resolution. Furthermore, no prior study on peer victimization has tested the role of somatic empathy or positive empathy, likely due to the lack of self-report instrument for somatic empathy and positive empathy.

Testing the links between empathy and related constructs such as aggressive behavior and callous-unemotional traits are useful first steps in establishing the criterion and construct validity of CASES as a measure for empathy. Yet empathy is still treated as a unitary construct in this validation process, and a meaningful distinction across the domains and valence measured by CASES with related constructs are critically needed. Thus, in addition to testing whether reactive and proactive aggression were associated with empathy in different patterns, we also seek to examine the discriminant validity of the subscales of CASES by testing whether each form of aggression was associated with domains- and valence-specific empathy to different degrees. Given the preliminary evidence that cognitive and affective empathy were differentially linked to 
peer victimization (Caravita et al., 2010; Kokkinos \& Kipritsi, 2012), we assessed several forms of peer victimization to further establish the discriminant validity for the CASES subscales.

In sum, the current study aimed to replicate the findings in Raine and Chen (2018) in a Hong Kong youth sample to test the cross-culture generalizability of CASES. Raine and Chen (2018) tested CASES in a youth sample with only a moderate size $(n=428)$ and with a narrow age span (11-12 years old), whereas the current study, with a much large sample size $(n=4676)$, extends the use of CASES for a wider age range from late childhood to adolescence. Specifically, this study sought to test: a) the factor structure in a large Hong Kong youth sample with a wider age range; b) the criterion and construct validity of CASES with callousunemotional traits, externalizing symptoms, aggression and anxiety/depression; c) the discriminant validity of CASES and its subscales with different forms of aggression; and d) the differential associations between the CASES subscales and varying victimization experiences.

We predicted that empathy scores from CASES would be inversely correlated with callous-unemotional traits and externalizing symptoms (rule-breaking and aggressive behavior), but not correlated with internalizing symptoms (anxiety/depression). Raine and Chen's study (2018) revealed moderate to strong effect sizes of sex differences in empathy. Hence we expected males to be lower on empathy. In addition, empathy scores would be negatively correlated with proactive aggression but positively correlated with reactive aggression, replicating the prior findings (Raine \& Chen, 2018). We also predicted that domains of empathy would be associated with proactive and reactive aggression with different magnitudes. Furthermore, we anticipated differential associations of empathy sub-scores and forms of peer victimization. Last, we predicted that when associations were found between empathy and CU 
traits/aggression/victimization, the associations would be stronger for negative empathy than positive empathy.

\section{Method}

\section{Participants}

Participants consisted of youth in primary and secondary schools in Hong Kong. Of the 153 schools whose representatives filled out consent and application forms for joining the research project, 25 schools (13 primary schools and 12 secondary schools) were randomly selected to ensure that each of the 18 regions in Hong Kong had at least one school represented in this research project. All Grade 4 to 9 students from these schools were invited to fill out questionnaires, and some of their parents were also invited to fill out related questionnaires. Parental consent and child assent were obtained before the study. Ethical approval for human research was obtained from the research committee of the City University of Hong Kong.

The current study focused on 4676 youth aged 8 to 18 years old who filled out CASES. Of the 4676 participants (62\% male) in the final analytic sample, $48 \%$ were in primary school, and $52 \%$ were in secondary school. The participants, on average, were 11.80 years old $(S D=$ 2.19). Socioeconomic status was only collected for youth in secondary schools: the median monthly family income bracket was 10001 to 20000 HKD (1282 to 2564 US dollars) and only $11 \%$ received the Comprehensive Social Security Assistance (welfare support).

\section{Measures}

Cognitive, affective and somatic empathy scales (CASES). The CASES are a 30-item self-report instrument used to assess empathy across three different domains and two valences. It was developed and validated in a predominantly African American (80\%) sample of urban youth age 11-12-year-old in the United States (Raine \& Chen, 2018). The three domains of empathy 
include cognitive, affective, and somatic, and each domain is measured with five negative and five positive items. Cognitive items reflected the perspective-taking ability, affective items assess the individuals' experiencing the emotion of another person, and somatic items assess a motor mimicry of the emotion in question or a somatic response to an emotional event. Detailed questionnaire items can be found in Table 1 .

The CASES were first translated to traditional Chinese by a native Cantonese speaking psychologist with proficiency in English. After that, the Chinese version was translated back into English by a group of local undergraduates in Hong Kong. The back-translations were examined by one of the authors for fidelity to the English version. Cycles of forward and back translations were completed when the back-translated version was close to the original CASES.

Callous-unemotional traits $(\mathbf{C U})$. The $\mathrm{CU}$ traits were assessed with both parent reports and child reports using the Antisocial Process Screening Device (ASPD; Frick \& Hare, 2001). Children and their caretakers responded to items on a 3-point scale $(0=$ not at all true $; 2=$ definitely true). To decrease the response burden for young children, we only asked youth in the secondary schools to self-report CU traits $(n=2427,100 \%$ response rate; Cronbach's $\alpha=.58)$. The ASPD has been validated with this Hong Kong youth sample (Fung, Gao, \& Raine, 2009). Only 55\% of all parents completed their assessment on the CU traits of their children (50\% in primary schools; Cronbach's $\alpha=.58)$. Overall, $27.16 \%$ of youth $(n=1270)$ had both parent- and self-report CU traits.

Child behavior checklist (CBCL). The CBCL is a widely used parent-report instrument for assessing a wide range of symptoms with evidence of high reliability/validity in many countries (Achenbach \& Rescorla, 2001). In the current study, due to time constraints on testing, we only administered three of subscales, rule-breaking behavior, aggressive behavior, and 
anxiety/depression, to examine the convergent and discriminant validity of CASES. Only parents of youth in secondary schools $(n=2427)$ were asked to complete the CBCL, and $47 \%$ of them completed CBCL. The three subscales have good internal consistency with Cronbach's alpha ranging from .85 to .90 .

Reactive-proactive aggression questionnaire (RPQ). The 23-item RPQ (Raine et al., 2006) was administered to collect parent- and child-report aggression. Children responded on a 3-point scale $(0=$ never, $1=$ sometimes, $2=$ always $)$ to 11 statements that assess their reactive aggression (RA; e.g., "yelled at others when they have annoyed you") and to 12 statements that assess proactive aggression (PA; e.g., "used force to obtain money or things from others"). The RPQ has been adapted for use in a Hong Kong youth sample different from the current study sample (Fung, Raine, \& Gao, 2009), and has a reading age of 8 years (Grade 2). The self-report RPQ has good internal consistency in this sample for RA $(\alpha=.83)$ and PA $(\alpha=.89)$. Scores were summed from the corresponding items on the subscales to form scores of RA and PA. Only 55\% of all inviting parents completed PA and RA assessment of their children (48\% in primary schools). Parent-report RPQ had good internal consistency for RA $(\alpha=.82)$ and PA $(\alpha=.85)$.

Multidimensional peer victimization scale (MPVS). This is a 16-item self-report measure for four forms of victimization (Mynard \& Joseph, 2000), including physical victimization (e.g., "punched me”), verbal victimization (e.g., "called me names”), social manipulation (e.g., "tried to make my friends turn against me"), and attacks on property (e.g., "deliberately damaged some property of mine"). Respondents reported on how often $(0=$ not at all, $1=$ once, $2=$ twice, $3=$ three times, $4=$ four times or more) during the school year they experienced the victimization. A systematic review showed that MPVS has good psychometric properties and produces reliable scores (Joseph \& Stockton, 2018). The Chinese version of the 
MPVS (Fung et al., 2017) was adopted in this study. Items were dichotomized to indicate whether a certain victimization experience occurred and then summed to form a variety score. For example, the verbal victimization subscale sum score indicates how many different verbal victimization experiences the youth had during the school year. The dichotomized items on each of the four subscales had acceptable internal consistency, with Cronbach's $\alpha$ of $.84, .82, .73$ and .73 for physical victimization, verbal victimization, social manipulation and attacks on property, respectively.

\section{Analysis Plan}

Analyses were conducted in Mplus 8 (Muthén \& Muthén, 1998-2017) using maximum likelihood estimation with robust standard errors. Similar to the approach used in the development of CASES (Raine \& Chen, 2018), we tested a series of confirmatory factor analyses and compared the model fit differences in the nested models with increasing constraints over the parameters and decreasing degree of freedoms. We evaluated the model fit with the $\chi^{2}$ test, the Comparative Fit Index (CFI), and the Root Mean Square Error of Approximation (RMSEA - Hu $\&$ Bentler, 1998). Because of the non-normality of the indicators, we used the Satorra-Bentler scaled $\chi^{2}$ where the usual normal-theory $\chi^{2}$ statistic is divided by a scaling correction to better approximate chi-square under non-normality (Bryant \& Satorra, 2012; Satorra \& Bentler, 2001). A model is regarded as to fit the data well if the $\chi^{2}$ test is not significant, if the CFI has a value above .90 , and the RMSEA has a value below .05 . However, note that with a large sample size in our study ( $n=4676)$, the $\chi^{2}$ test is sensitive to sample size and is likely to be significant. We tested the nested model difference in fitting the data with the $\chi^{2}$ difference test with the Satorra- 
Bentler scaling correction ${ }^{1}$ (Satorra $\&$ Bentler, 2001). If the $\chi^{2}$ difference is significant, it suggests that the model fit gets significantly worse when more constraints are imposed on the model.

Second, we tested whether each facet of empathy could be reliably decomposed into positive and negative valence by comparing two nested second-order factor models. The first second-order model (Model 4) had three first-order factors (cognitive, affective, somatic) which were then loaded onto one second-order factor. The second second-order model (Model 5) was nested in Model 4 and consisted of six first-order factors (cognitive, affective, somatic - each in both positive and negative forms) which were loaded on one second-order factor.

To evaluate reliability, we used Cronbach's $\alpha$ for each subscale of empathy based on the one-, two-, three- and six-factor models. For concurrent validity, we examined correlations between empathy scales and self- and parent-report $\mathrm{CU}$ traits. We also examined sex differences in empathy. Next, we tested the correlation between empathy and rule-breaking behavior/ aggressive behavior for convergent validity, and between empathy and anxiety/depression for discriminant validity. Additional construct validity tests included zero-order correlations of empathy with proactive and reactive aggression, followed by partial correlations in which correlations between empathy and proactive aggression were controlled for reactive aggression, and vice versa. Moreover, we examine whether different domains and valance of empathy may be differentially correlated with multidimensional peer victimization experiences.

Last, to examine the cross-culture replication of the association between CASES and other constructs, we correlated the coefficients from this study with the corresponding ones

\footnotetext{
${ }^{1}$ Scaled $\chi 2$ difference $=(F 0 c 0-F 1 c 1)(d 0-d 1) /(c 0 d 0-c 1 d 1)$ using the Mplus 8 output, where $F 0 c 0$ and $d 0$ are the $\chi 2$ value, scaling factor, and degree of freedom from the constrained model, and F1, $c 1$, and $d 1$ are the $\chi 2$ value, scaling factor and degree of freedom from the freely estimated model
} 
reported in Raine and Chen (2018). For example, when testing how similar the 12 correlation coefficients between empathy scores (total scores and the subscale scores from CASES) and selfreport CU in the current study and in the Raine and Chen (2018), we ran a zero-order correlation analysis on the 12 pairs of correlation coefficients to get one correlation coefficient to reveal how similar the associated patterns were between CASES scores and CU traits across the two studies.

\section{Results}

\section{Comparison between Nested Models with Different Factors}

Model fit indices are summarized in Table 2. Support was provided for both a two-factor structure (positive-negative empathy, Model 2) and a three-factor structure (cognitive-affectivesomatic empathy, Model 3). These two models fit the data well as shown by their respective model fit indices, with RMSEA in both cases close to .05. Compared with a one-factor model, the two-factor model had a highly significant better fit as seen in the Satorra-Bentler Scaled chisquare difference test $(\Delta \chi 2(1)=428.39, p<.001)$, as did the three-factor model $(\Delta \chi 2(3)=$ $1024.95, p<.001)$. The factor loadings of items in Model 1-3 ranged from .35 to .69 with at least half of factor loadings above .50 .

We tested two nested models which contain a higher-order factor which differed with respect to whether each domain of empathy was separated into positive and negative factors. The first one (Model 4) was essentially the same model as Model 3 with a second-order factor capturing the intercorrelation between the three domains, whereas the other model (Model 5) broke the three facets into positive and negative valence to yield six first-order factors. In Model 4 , the second-order factor of empathy accounted for $66 \%, 96 \%$ and $94 \%$ of the variance in cognitive, affective and somatic empathy (i.e., the first-order factors). In Model 5, the secondorder empathy factor accounted for $55 \%$ to $90 \%$ of the variance in the six first-order factors. As 
reported in Table 2, Model 5 had a significantly better fit than Model 4. This indicates that cognitive, affective, and somatic empathy can all be validly separated into positive and negative forms; and in doing so, the model fit is improved. The factor loadings of items in Model 4 ranged from .38 to .64 with two-thirds of factor loadings above .50 , and the factor loadings of items in Model 5 ranged from .37 to .70 with over three-quarters of factor loadings above .50 .

\section{Internal Consistency of Empathy Subscales and Sex Differences in Empathy}

We reported means and standard deviations for the total sample and by sex in Table 3. Following the previous work on CASES (Raine \& Chen, 2018), we computed empathy scores in several ways, including an overall empathy score, two empathy scores for positive and negative forms across domains, three domain-specific empathy scores, and six domain and valence specific empathy scores (e.g., affective empathy score for positive emotions; hereafter termed affective-positive empathy scores). The internal consistency measured as Cronbach's alpha was excellent except for some domain and valence specific empathy scores which comprised only 5 items. The magnitudes of item-total correlations for each subscale were moderate to large. Females scored higher than males on all empathy scales with moderate to large effect sizes based on Cohen's d.

\section{Concurrent Validity}

All subscales of CASES were significantly correlated with both self- and parent-report CU traits, with high empathy being associated with lower CU scores. The magnitudes of the correlation between empathy scales and CU traits are moderate to large when using self-report $\mathrm{CU}$ traits $(r \mathrm{~s}=-.49$ to -.28$)$ but were small when using parent-report $\mathrm{CU}$ traits $(r s=-.15$ to -.11$)$; see Table 4). Parent-and self-report CU traits were only weakly correlated $(r=.16)$.

\section{Construct Validity: Convergent and Discriminant Validity}


As seen in Table 4, empathy scores were inversely correlated with rule-breaking behavior but not with anxious/depressive symptoms, with some exceptions. Contrary to our hypothesis, none but one empathy score was correlated with aggressive behavior as assessed by the CBCL.

Quite different results emerged from the analysis of sub-forms of aggression (see Table 5). Self-report RA was positively correlated with 11 of the 12 empathy scores, whereas selfreported PA was negatively correlated with 10 of the 12 empathy scores. In contrast, total aggression was not consistently linked to empathy scores, paralleling findings from the CBCL aggression measure. Given the moderate correlation between PA and RA $(r=.62)$, we adjusted for this by testing the partial correlation. As shown in Table 5, RA was positively correlated with all empathy scores, and PA was negatively correlated with all empathy scores, with magnitudes appearing larger than those in the zero-order correlations.

We further tested the magnitudes of the correlation coefficients of RA and PA with different domains of empathy using Fisher's $r$ to $z$ transformation and the asymptotic covariance (Lee \& Preacher, 2013). We found that based on zero-order correlation, RA correlated the strongest with somatic empathy as compared to affective $(z=2.22, p=.03)$ or cognitive empathy $(z=3.78, p<.001)$, but it correlated with affective and cognitive empathy to a similar extent $(z=$ $1.55, p=.12$ ). In contrast, PA correlated negatively with affective empathy more strongly than cognitive empathy $(z=2.03, p=.04)$, and it correlated more strongly with cognitive empathy than with somatic empathy $(z=1.76, p=.08)$.

The correlations between empathy scores and parent-report RA or RA were largely negative, and PA was more consistently correlated with empathy scores than RA. The total aggression score was negatively correlated with 11 of the 12 empathy scores. Adjusting for PA, parent-report RA was not correlated with any of the empathy scores. In contrast, adjusting for 
RA, parent-report PA was still correlated with all the empathy scores, though the correlations coefficients did not differ significantly across domains or valences of empathy.

\section{Empathy-Victimization Associations}

Bivariate correlations between empathy and victimization are reported in Table 6 .

Overall, the magnitudes for most correlations were small. The total empathy score was negatively correlated with physical victimization, positively correlated with social manipulation and verbal victimization, but uncorrelated with attack on property. Regarding valence of empathy, physical victimization, and social manipulation, though in opposite directions, were correlated only to negative forms of empathy whereas verbal victimization was correlated with both negative and positive forms of empathy. Regarding domains of empathy, physical victimization was inversely correlated with cognitive empathy, whereas social manipulation and verbal victimization were positively correlated with both affective and somatic empathy. Attack on property was correlated with somatic empathy alone.

\section{Cross-study Correlations}

The correlation of sex differences in 12 empathy scores across the two studies was strong $(r=.61)$ and statistically significant. Similarly, the reliability of the empathy subscales was highly correlated across the two studies $(r=.95)$. The relationships between empathy scores and self-report CU scores, and between empathy scores proactive aggression were significantly correlated across the two studies and were large in magnitude ( $r=.80$ and .78 , respectively). However, the findings were not as similar across the two studies in the relationships between empathy scores and parent-report reactive/proactive aggression or self-report reactive aggression. Results remained the same when adjusting for the item number of each empathy scale.

\section{Assessing Bias due to Missingness}


To reduce the burden on younger children, self-report $\mathrm{CU}$ traits were only administered in secondary schools. Youth from secondary schools had higher cognitive empathy, but lower affective and somatic empathy than youth from primary schools, but they did not differ in positive and negative empathy or total empathy scores. Among youth in secondary schools, those with missing CBCL scored higher on all empathy subscales than those with non-missing CBCL.

The parent-report CU traits and PA/RA only had a 55\% response rate and responses were evenly distributed in primary schools and secondary schools. Parents who returned their assessment of the child's CU traits also completed the PA and RA assessment (97\% overlap). Youth with missing data on parent report CU or PA/RA scored higher on all empathy subscales than those with non-missing data on these parent-report assessments.

\section{Discussion}

This study aimed to validate the use of an empathy measure (CASES) that assesses cognitive, affective and somatic empathy and both positive and negative valence in a large Hong Kong youth sample, and to explore the links between empathy and proactive/reactive aggression, and between empathy and peer victimization. We validated this instrument using a higher-order age span (8 to 18 years) than used in the original development of CASES (11 to 12 years). Consistent with the original development of CASES in the US (Raine \& Chen, 2018), we found support for the distinction between cognitive, affective and somatic empathy, the distinction between positive and negative empathy, as well as the further distinction of each domain of empathy with two valence facets. The internal consistency for the empathy subscales is good except for the shorter 5-item subscales. We established concurrent validity of CASES with both parent- and self-report callous-unemotional traits. Convergent validity of CASES was supported by its correlation with relevant constructs such as rule-breaking behavior. Discriminant validity 
was established by the null association with anxiety/depression and the differential associations with proactive aggression and reactive aggression. Last, we revealed differential links between domains and valence facets of empathy and types of peer victimization experiences and aggression. Consistent with the prior study (Raine \& Chen, 2018), we found sex differences in empathy with moderate to strong effect sizes. Of note, the means of the empathy scores in the current study were very similar to those in Raine and Chen (2018), with cross-study correlations revealing similar associative patterns between empathy scores and related constructs (e.g., CU scores, sex differences). The current study provides support for the multifaceted nature of empathy which can be captured in a brief self-report instrument, and the cross-culture generalizability of this instrument to an Asian culture.

We established cross-cultural generalizability by replicating the findings of the confirmatory factor analyses of the CASES from Raine and Chen (2018). Attention is warranted that the CFIs of all the nested models are generally lower than the set criteria of .90, which suggested that the proposed model did not fit the data as well as we hope. However, other model fit indices such as RMSEA are acceptable, and the model fit increase significantly based on the chi-square difference tests for the more sophisticated multi-factor models. Specifically, the CFA revealed that the model identifying cognitive, affective and somatic empathy fit the data better than that with only one general empathy factor. The distinction of the three empathy domains in self-report measures in a Hong Kong sample can facilitate studies with a focus on cross-culture comparisons in empathy, and with a focus on the evaluation of similarities and differences between subjective and objective measures (EMG, fMRI) of various domains of empathy.

Our study also documented that the model with positive and negative empathy outperformed the single-factor model, suggesting that empathetic responding to positive and 
negative valences are not equivalent. This is in line with the long-established notion that positive and negative affect involves distinct psychological processes. For example, Van der Graaf (2016) revealed that when processing negative affect (viewing sad film clips) as compared to positive affect (viewing happy film clip), trait and state empathy were linked more strongly. Given that positive and negative affect are linked to varying psychopathological outcomes (Hughes \& Kendall, 2009; Steptoe, Dockray, \& Wardle, 2009), an instrument that can distinguish positive and negative empathy may be useful in a clinical context. To date, CASES is the only instrument that makes this distinction. It is worth noting that although the nested model comparison in the CFA provided support for a further breakdown of each of the empathy domains into positive and negative valences, the internal consistency of these shorter subscales was lower. As such, caution is warranted when empathy of a particular domain with specific valence (e.g., cognitive-negative empathy) is used in future studies.

In addition to documenting factor structure replicability, it is critical to establish criterion and construct validity. The concurrent validity of all the CASES subscales were good based on the correlations with the existing callous-unemotional traits measure (Frick \& Hare, 2001). The parent- and self-report CU traits lent converging evidence for the empathy measures. In addition to affective empathy, both cognitive and somatic empathy were negatively correlated with CU traits, suggesting a uniform reduction in empathy across domains among individuals with high levels of CU traits. The magnitude of the relationship was much larger using self-report CU traits. However, it is unclear whether the higher correlation between self-report CU traits and empathy is due to common method issues (both are self-report) or whether self-report CU traits may have better construct validity than parent-reports. Tentative evidence for the latter is that, when accounting for self-report CU traits, the parent-report CU traits were only correlated with 
cognitive and somatic empathy but not affective empathy (results available upon request). It is possible that affective empathy may be more reliably assessed via self-report given that it is hard for a parent to observe the youth's empathetic emotional responding and experiences.

Nevertheless, with a relatively low parent-child correlation on CU traits, the converging evidence from both informants is encouraging in revealing that the low empathy scores captured by CASES may underly both parent- and self-report CU traits.

We found support for the convergent validity of the empathy scores with rule-breaking behavior, and discriminant validity based on the null correlation with unrelated constructs such as depression/anxiety. Individuals with low levels of empathy, be it cognitive, affective or somatic, have higher levels of rule-breaking behavior, possibly because they more readily adopt rule-breaking behavior due to a lower ability to take the perspective of others, and to feel others' suffering, compared to someone who is more empathetic towards other individuals. Females consistently scored higher on all empathy subscales than males, consistent with prior research findings using self-report measures (Derntl et al., 2010; Rueckert \& Naybar, 2008).

Examination of the relationships between empathy and different forms of aggression revealed differential findings that shed light on the prior mixed literature on aggression and empathy. Although we did not find a consistent association between empathy and aggressive behavior as measured by the CBCL or between empathy and the total RPQ aggression score, empathy scores did have differential associations with proactive and reactive aggression. When adjusting for the other aggression, empathy scores were negatively associated with self- and parent-report proactive aggression, and had either null (parent-report) or positive (self-report) relationships with reactive aggression. These findings were in line with those from the US sample (Raine \& Chen, 2018) as well as another study using a different Hong Kong youth 
sample (Fung et al., 2015). Fung and colleagues found that children with high proactive aggression had less warmth, concern, and feelings for others, whereas children with high reactive aggression experienced and expressed more anger.

The distinction of aggression into "cold-blooded" and "hot-blooded" may help elucidate the differential empathy-aggression links. Blair (2018) argued that individuals could more readily employ aggression as a means to obtain power, property, and dominance when these empathic mechanistic processes are compromised. Thus, it is not surprising that proactive aggression may be displayed more by individuals who have low empathy. In contrast, those with high levels of reactive aggression may be the ones with trouble regulating their emotion and/or with hostile bias in attribution which reflects deficits in social information processing (Crick \& Dodge, 1996; Dodge \& Coie, 1987; Raine et al., 2006), which could result in the heightened emotional (internal) experiences that are reflected in self-report CASES but not in parent-report CASES. The opposite direction (positive versus negative, positive versus null) for the link of proactive and reactive aggression with empathy may explain why there was a null association in general for empathy and total aggression or empathy and aggressive behavior in this study, as well as the weak empathy-aggression association in the meta-analysis (Vachon et al., 2014). Our findings also provide additional support for the utility of distinguishing aggression into proactive and reactive forms despite their moderate correlations, in line with prior research that delineated different biological and psychological antecedents to the two forms of aggression (Card \& Little, 2006; Chen, Raine, \& Granger, 2018).

We have established concurrent and construct validity of CASES in the Hong Kong sample through the association (and lack thereof) of several related and unrelated constructs. All associations found are typically similar across all domains and valences of the empathy scales 
measured with CASES with the exception of the relationships with self-report reactive/proactive aggression. Reactive aggression was linked most strongly to somatic empathy whereas proactive aggression was most strongly linked to affective empathy. We also revealed better fitting of the data in confirmatory factor analyses with domain-specific empathy and valence-specific empathy, but it is still important to investigate whether there are differential links with other constructs for different domains/valences of empathy.

We hypothesized that different domains/facets of empathy might provide utility when studying victimization experience. We found preliminary support for this hypothesis, with distinct associations patterns, but the small magnitude of effects warrant due caution. The null associations are likely to be true given that a sample size as large as 4000 should allow detection of even small effect sizes. Furthermore, the statistically significant findings in this section may include associations that are of small magnitudes and may not be readily detectable with small sample sizes in future studies.

Physical victimization was negatively correlated with cognitive empathy. The perspective-taking ability assessed with cognitive empathy appeared to play a protective role against physical victimization based on the negative correlation between the two. Those who are better at perspective-taking and adopting other's viewpoint may be better at resolving conflicts and defusing a confrontational situation to avoid physical victimization. Cognitive empathy did not seem to lower or heighten the risk for other forms of victimization.

In contrast, affective and somatic empathy were important in social manipulation and verbal victimization. The positive correlations between affective empathy and social manipulation and verbal victimization are not novel as similar prior findings have been reported for 10- to 13-year-olds (Kokkinos \& Kipritsi, 2012) and also in a preschool sample (Garner \& 
Lemerise, 2007), but findings regarding somatic empathy are new. Researchers have suggested that some bullies with "theory of nasty minds" may understand others' emotions but do not share them (Sutton, Smith, \& Swettenham, 1999), and some have hypothesized that when the victim displays distress, this may further intensify the bullies' behavior (Davis, 2018). It is possible that heightened sensitivity to experience the emotion of others and somatic mimicry of emotional events lead these youth to a more vulnerable position for social manipulation and verbal abuse. Alternatively, heightened somatic and affective empathy could be the result of victimization. That is, youth who experience more social manipulation and verbal victimization may be more sensitive to the emotional consequences as a result to more exposure to rule transgressions (Garner \& Lemerise, 2007; Mavroveli, Petrides, Sangareau, \& Furnham, 2009). With a crosssectional design, we cannot disentagle the temporal order of empathy and victmization experience. Additionally, as both empathy and victimization were self-reported, we cannot rule out the possibility of reporting bias due to common methods .

We also revealed a link between somatic empathy with attack on property. It is unclear why youth with a high level of somatic response or tendency for motor mimicry of emotion would experience more attacks on their property and replication studies are needed. Conceivable, bullies derive more pleasure seeing their victims cringe and display more outward emotions via somatic responses which further reinforces the bullies' behavior of attacking the victim's property (Sutton et al., 1999). Future studies can incorporate objective measures such as EMG to further disentangle whether our findings are largely due to common method bias (self-report) or can be validated with objective measures such as EMG. It is worth pursuing and furthering this line of research to disentangle the temporal order of various domains/ forms of empathy and victimization and the dynamics between bullies and victims. 
We did not find differential associations between the valence of empathy and various correlates. That is, positive and negative empathy appeared to be associated with CU traits, forms of aggression and peer victimization with similar magnitudes, unlike what we predicted. We did not elect to lump the positive and negative affect to get a more parsimonious model because this is among the first studies to examine a self-report empathy scale with positive and negative valence and we only included limited correlates to test these relationships. At this early stage of developing the CASES, we opt to act more conservative to keep the valence components separate for further testing. Furthermore, this is a community sample and the differential associations may be more readily found in a clinical sample. More empirical studies with diverse outcomes (e.g., prosocial behavior) and diverse samples (e.g., clinical samples) are needed before we can conclude the lack of utility of the distinction of valence in empathy. With the emerging interest in studying positive empathy (Morelli et al., 2015), we believe the distinction of valence in CASES will provide a useful tool to be incorporated in future research.

Findings should be interpreted in light of several limitations. First, this is a crosssectional study and cannot be used for causal inference for the relationship between variables. Second, some validity tests of CASES relied on self-report measures which don't preclude the common method bias. We did include parent-report measures whenever possible, and results from parent-report typically converge with self-report in the current study, albeit at a more modest level. Third, due to time limitations for administering the questionnaires, not all measures could be included in the entire sample, although the sample sizes were still relatively large (over 2000 except for the CBCL). Last, there was a relatively low response rate (55\%) for parentreport instruments for validity test of CASES. We assessed the potential bias and it is of note that youth with higher empathy scores were missing on such parent-report instruments. 
The current study replicated most of the findings of an empathy instrument (CASES) in a large sample of over 4,000 Hong Kong youth. We extend the use of CASES from the youth of 11-12 years old in the initial study (Raine \&Chen, 2018) to youth age 8-18 years old. We found support for the reliability and validity of scores on an empathy instrument that includes new elements such as empathy with positive and negative valence and somatic empathy. We also found preliminary evidence for differential links of domain-specific empathy with different forms of aggression and different forms of peer victimization. The mechanism of the empathypeer victimization link warrants further investigation. The validation of a multi-faceted selfreport empathy scale can facilitate longitudinal research that examines the development of empathy in different domains and allows testing of the convergence/ divergence of physiological measures with this self-report empathy measure.

\section{Acknowledgments}

This work was supported by the General Research Fund, University Grant Council under Grant 11402514.

\section{Declaration of Interest Statement}

The authors declared no potential conflicts of interest with respect to the research, authorship, and/or publication of this article. 


\section{References}

Atkins, M. S., \& Stoff, D. M. (1993). Instrumental and hostile aggression in childhood disruptive behavior disorders. Journal of Abnormal Child Psychology, 21(2), 165-178. doi:10.1007/Bf00911314

Austin, G., Bondü, R., \& Elsner, B. (2017). Longitudinal relations between children's cognitive and affective theory of mind with reactive and proactive aggression. Aggressive Behavior, 43(5), 440-449.

Batanova, M. D., \& Loukas, A. (2011). Social anxiety and aggression in early adolescents: Examining the moderating roles of empathic concern and perspective taking. Journal of Youth and Adolescence, 40(11), 1534-1543.

Bernhardt, B. C., \& Singer, T. (2012). The neural basis of empathy. Annual Review of Neuroscience, 35, 1-23.

Blair, R. (2018). Traits of empathy and anger: Implications for psychopathy and other disorders associated with aggression. Philosophical Transactions of the Royal Society B: Biological Sciences, 373(1744), 20170155. doi:10.1098/rstb.2017.0155

Blair, R. J. R. (2005). Responding to the emotions of others: Dissociating forms of empathy through the study of typical and psychiatric populations. Consciousness and cognition, 14(4), 698-718.

Bryant, F. B., \& Satorra, A. (2012). Principles and practice of scaled difference chi-square testing. Structural Equation Modeling: A Multidisciplinary Journal, 19(3), 372-398.

Caravita, S. C., Di Blasio, P., \& Salmivalli, C. (2009). Unique and interactive effects of empathy and social status on involvement in bullying. Social Development, 18(1), 140-163. 
Caravita, S. C., Di Blasio, P., \& Salmivalli, C. (2010). Early adolescents' participation in bullying: Is tom involved? The Journal of Early Adolescence, 30(1), 138-170.

Card, N. A., \& Little, T. D. (2006). Proactive and reactive aggression in childhood and adolescence: A meta-analysis of differential relations with psychosocial adjustment. International Journal of Behavioral Development, 30(5), 466-480. doi:10.1177/0165025406071904

Chen, F. R., Raine, A., \& Granger, D. A. (2018). Testosterone and proactive-reactive aggression in youth: The moderating role of harsh discipline. Journal of Abnormal Child Psychology, 46, 1599-1612. doi:10.1007/s10802-018-0399-5

Clark, M. A., Robertson, M. M., \& Young, S. (2019). "I feel your pain”: A critical review of organizational research on empathy. Journal of Organizational Behavior, 40(2), 166-192.

Crick, N. R., \& Dodge, K. A. (1996). Social information-processing mechanisms in reactive and proactive aggression. Child Development, 67(3), 993-1002.

Cuff, B. M., Brown, S. J., Taylor, L., \& Howat, D. J. (2016). Empathy: A review of the concept. Emotion Review, 8(2), 144-153.

Davis, M. H. (1983). Measuring individual differences in empathy: Evidence for a multidimensional approach. Journal of Personality and Social Psychology, 44(1), 113.

Davis, M. H. (2018). Empathy: A social psychological approach: Routledge.

Derntl, B., Finkelmeyer, A., Eickhoff, S., Kellermann, T., Falkenberg, D. I., Schneider, F., \& Habel, U. (2010). Multidimensional assessment of empathic abilities: Neural correlates and gender differences. Psychoneuroendocrinology, 35(1), 67-82. 
Dodge, K. A., \& Coie, J. D. (1987). Social-information-processing factors in reactive and proactive aggression in children's peer groups. J Pers Soc Psychol, 53(6), 1146-1158. doi:10.1037/0022-3514.53.6.1146

Endresen, I. M., \& Olweus, D. (2001). Self-reported empathy in norwegian adolescents: Sex differences, age trends, and relationship to bullying. In B. A. C. \& S. D. J. (Eds.), Constructive and destructive behavior: Implications for family, school, \& society (pp. 147-165). Washington DC: American Psychological Association.

Espelage, D. L., Mebane, S. E., \& Adams, R. S. (2004). Empathy, caring, and bullying: Toward an understanding of complex associations. In D. L. Espelage \& S. M. Swearer (Eds.), Bullying in American schools: A social-ecological perspective on prevention and intervention (pp. 37-61): Routledge.

Farrington, D. P., \& Ttofi, M. M. (2009). School-based programs to reduce bullying and victimization. The Campbell Collaboration, 6, 1-149.

Frick, P. J., \& Hare, R. D. (2001). The antisocial process screening device. Toronto: MultiHealth Systems.

Frick, P. J., \& White, S. F. (2008). Research review: The importance of callous-unemotional traits for developmental models of aggressive and antisocial behavior. Journal of Child Psychology and Psychiatry, 49(4), 359-375. doi:10.1111/j.1469-7610.2007.01862.x

Fung, A. L. C., Gao, Y., \& Raine, A. (2009). The utility of the child and adolescent psychopathy construct in Hong Kong, China. Journal of Clinical Child and Adolescent Psychology, 39(1), 134-140. 
Fung, A. L. C., Gerstein, L. H., Chan, Y., \& Engebretson, J. (2015). Relationship of aggression to anxiety, depression, anger, and empathy in Hong Kong. Journal of Child and Family Studies, 24(3), 821-831.

Fung, A. L. C., Raine, A., \& Gao, Y. (2009). Cross-cultural generalizability of the reactiveproactive aggression questionnaire (RPQ). Journal of Personality Assessment, 91(5), 473-479.

Fung, A. L. C., Tsang, E. Y. H., Zhou, G., Low, A. Y. T., Ho, M. Y., \& Lam, B. Y. H. (2017). Relationship between peer victimization and reactive-proactive aggression in school children. Psychology of Violence, Advance online publication. doi:10.1037/vio0000125

Garner, P. W., \& Lemerise, E. A. (2007). The roles of behavioral adjustment and conceptions of peers and emotions in preschool children's peer victimization. Development and Psychopathology, 19(1), 57-71.

Gini, G., Albiero, P., Benelli, B., \& Altoè, G. (2007). Does empathy predict adolescents' bullying and defending behavior? Aggressive Behavior, 33(5), 467-476. doi:10.1002/ab.20204

Hein, G., \& Singer, T. (2008). I feel how you feel but not always: The empathic brain and its modulation. Current Opinion in Neurobiology, 18(2), 153-158.

Hughes, A. A., \& Kendall, P. C. (2009). Psychometric properties of the positive and negative affect scale for children (PANAS-C) in children with anxiety disorders. Child Psychiatry and Human Development, 40(3), 343-352.

Jolliffe, D., \& Farrington, D. P. (2004). Empathy and offending: A systematic review and metaanalysis. Aggression and Violent Behavior, 9(5), 441-476.

Joseph, S., \& Stockton, H. (2018). The multidimensional peer victimization scale: A systematic review. Aggression and Violent Behavior, 42, 96-114. 
Kokkinos, C. M., \& Kipritsi, E. (2012). The relationship between bullying, victimization, trait emotional intelligence, self-efficacy and empathy among preadolescents. Social Psychology of Education, 15(1), 41-58.

Lee, I. A., \& Preacher, K. J. (2013). Calculation for the test of the difference between two dependent correlations with one variable in common. Retrieved from http://quantpsy.org

Mavroveli, S., Petrides, K. V., Sangareau, Y., \& Furnham, A. (2009). Exploring the relationships between trait emotional intelligence and objective socio-emotional outcomes in childhood. British Journal of Educational Psychology, 79(2), 259-272.

Mavroveli, S., Petrides, K. V., Sangareau, Y., \& Furnham, A. (2009). Exploring the relationships between trait emotional intelligence and objective socio-emotional outcomes in childhood. British Journal of Educational Psychology, 79(2), 259-272.

Morelli, S. A., Lieberman, M. D., \& Zaki, J. (2015). The emerging study of positive empathy. Social and Personality Psychology Compass, 9(2), 57-68.

Muthén, L. K., \& Muthén, B. O. (1998-2017). Mplus user's guide. Eighth edition. Los Angeles, CA: Muthén \& Muthén.

Mynard, H., \& Joseph, S. (2000). Development of the multidimensional peer-victimization scale. Aggressive Behavior: Official Journal of the International Society for Research on Aggression, 26(2), 169-178.

Pardini, D. A., Lochman, J. E., \& Powell, N. (2007). The development of callous-unemotional traits and antisocial behavior in children: Are there shared and/or unique predictors? Journal Of Clinical Child And Adolescent Psychology, 36(3), 319-333.

Raine, A., \& Chen, F. R. (2018). The cognitive, affective, and somatic empathy scales (CASES) for children. Journal of Clinical Child and Adolescent Psychology, 47(1), 24-37. 
Raine, A., Dodge, K., Loeber, R., Gatzke-Kopp, L., Lynam, D., Reynolds, C., . . Liu, J. (2006). The reactive-proactive aggression questionnaire: Differential correlates of reactive and proactive aggression in adolescent boys. Aggressive Behavior, 32(2), 159-171. doi:10.1002/ab.20115

Rueckert, L., \& Naybar, N. (2008). Gender differences in empathy: The role of the right hemisphere. Brain and Cognition, 67(2), 162-167.

Satorra, A., \& Bentler, P. M. (2001). A scaled difference chi-square test statistic for moment structure analysis. Psychometrika, 66(4), 507-514.

Sebastian, C. L., McCrory, E. J. P., Cecil, C. A. M., Lockwood, P. L., De Brito, S. A., Fontaine, N. M. G., \& Viding, E. (2012). Neural responses to affective and cognitive theory of mind in children with conduct problems and varying levels of callous-unemotional traits. Archives of General Psychiatry, 69(8), 814-822.

doi:10.1001/archgenpsychiatry.2011.2070

Shamay-Tsoory, S. G., Aharon-Peretz, J., \& Perry, D. (2009). Two systems for empathy: A double dissociation between emotional and cognitive empathy in inferior frontal gyrus versus ventromedial prefrontal lesions. Brain, 132(3), 617-627.

Singer, T., Seymour, B., Doherty, J., Kaube, H., Dolan, R. J., \& Frith, C. D. (2004). Empathy for pain involves the affective but not sensory components of pain. Science, 303(5661), 1157-1162. doi:10.1126/science.1093535

Steptoe, A., Dockray, S., \& Wardle, J. (2009). Positive affect and psychobiological processes relevant to health. Journal Of Personality, 77(6), 1747-1776. 
Sutton, J., Smith, P. K., \& Swettenham, J. (1999). Bullying and 'theory of mind': A critique of the 'social skills deficit' view of anti-social behaviour. Social Development, 8(1), 117127.

Tone, E. B., \& Tully, E. C. (2014). Empathy as a "risky strength": A multilevel examination of empathy and risk for internalizing disorders. Development and Psychopathology, 26(4 Pt 2), 1547-1565.

Vachon, D. D., Lynam, D. R., \& Johnson, J. A. (2014). The (non) relation between empathy and aggression: Surprising results from a meta-analysis. Psychological Bulletin, 140(3), 751753.

Van der Graaff, J., Meeus, W., de Wied, M., van Boxtel, A., van Lier, P. A., Koot, H. M., \& Branje, S. (2016). Motor, affective and cognitive empathy in adolescence: Interrelations between facial electromyography and self-reported trait and state measures. Cognition and Emotion, 30(4), 745-761.

van Noorden, T. H. J., Haselager, G. J. T., Cillessen, A. H. N., \& Bukowski, W. M. (2015). Empathy and involvement in bullying in children and adolescents: A systematic review. Journal of Youth \& Adolescence, 44(3), 637-657. doi:10.1007/s10964-014-0135-6

Vitaro, F., Gendreau, P. L., Tremblay, R. E., \& Oligny, P. (1998). Reactive and proactive aggression differentially predict later conduct problems. Journal of Child Psychology and Psychiatry and Allied Disciplines, 39(3), 377-385. doi:10.1017/S0021963097002102 
Table 1

Cognitive, Affective and Somatic Empathy Scales Items and Factor Loadings for the Five Models $(n=4676)$

\begin{tabular}{|c|c|c|c|c|c|}
\hline Questionnaire Items on CASES & $\begin{array}{c}\text { Model 1: } \\
\text { One } \\
\text { Factor }\end{array}$ & $\begin{array}{l}\text { Model 2: } \\
\text { Two- } \\
\text { Factor } \\
\text { (Positive- } \\
\text { Negative) }\end{array}$ & $\begin{array}{l}\text { Model 3: } \\
\text { Three-Factor } \\
\text { (Cognitive- } \\
\text { Affective- } \\
\text { Somatic) }\end{array}$ & $\begin{array}{c}\text { Model 4: } \\
\text { Three First } \\
\text { Order Factors, } \\
\text { One Second } \\
\text { Order }\end{array}$ & $\begin{array}{c}\text { Model 5: } \\
\text { Six First- } \\
\text { Order Factors, } \\
\text { One Second } \\
\text { Order }\end{array}$ \\
\hline \multicolumn{6}{|l|}{ Cognitive - Positive } \\
\hline $\begin{array}{l}\text { 1. I know why my friends are cheerful even when they } \\
\text { don't say why }\end{array}$ & .37 & .38 & .43 & .43 & .38 \\
\hline $\begin{array}{l}\text { 17. I can understand how characters in an exciting story } \\
\text { feel }\end{array}$ & .50 & .49 & .46 & .46 & .50 \\
\hline $\begin{array}{l}\text { 9. When someone is in a good mood I can tell by how } \\
\text { they look and behave }\end{array}$ & .51 & .50 & 61 & .61 & .51 \\
\hline $\begin{array}{l}\text { 23. I know when my family members are pleased by how } \\
\text { they talk. }\end{array}$ & .56 & .55 & .62 & .62 & .56 \\
\hline $\begin{array}{l}\text { 28. I can put myself in someone else's shoes when they } \\
\text { describe being happy }\end{array}$ & .66 & .69 & .59 & .59 & .68 \\
\hline \multicolumn{6}{|l|}{ Cognitive - Negative } \\
\hline 6. I can tell when someone is feeling guilty & .42 & .43 & .52 & .52 & .55 \\
\hline $\begin{array}{l}\text { 18. I know when someone is unhappy even before they } \\
\text { say why }\end{array}$ & .49 & .49 & .59 & .59 & .62 \\
\hline $\begin{array}{l}\text { 21. When a friend is teased, I understand why they get } \\
\text { upset }\end{array}$ & .54 & .57 & .56 & .56 & .56 \\
\hline $\begin{array}{l}\text { 26. When someone is disappointed, I can tell by how } \\
\text { they look }\end{array}$ & .56 & .57 & 67 & 67 & .70 \\
\hline $\begin{array}{l}\text { 12. I can tell from their face and how they behave when } \\
\text { someone is ashamed }\end{array}$ & .45 & .46 & .56 & .56 & .58 \\
\hline \multicolumn{6}{|l|}{ Affective - Positive } \\
\hline 5. Watching little puppies playing makes me feel happy & .39 & .40 & .40 & .40 & .41 \\
\hline $\begin{array}{l}\text { 25. It makes me feel cheerful to see children running } \\
\text { around having fun }\end{array}$ & .64 & 67 & .66 & .66 & .68 \\
\hline
\end{tabular}




\begin{tabular}{|c|c|c|c|c|c|}
\hline 8. Hearing the cheer of a sports crowd gives me a thrill & .52 & .53 & .53 & .53 & .55 \\
\hline $\begin{array}{l}\text { 13. When I see people in a movie having an adventure, I } \\
\text { get excited }\end{array}$ & .49 & .50 & .51 & .51 & .52 \\
\hline $\begin{array}{l}\text { 22. I feel pleased when someone tells me some good } \\
\text { news they have just had }\end{array}$ & .59 & .60 & .60 & .60 & .62 \\
\hline \multicolumn{6}{|l|}{ Affective - Negative } \\
\hline $\begin{array}{l}\text { 2. If I saw my friend being made a fool of, I would feel } \\
\text { uncomfortable }\end{array}$ & .46 & .48 & .47 & .47 & .49 \\
\hline $\begin{array}{l}\text { 10. I would feel angry if I saw a man hitting a } \\
\text { defenseless woman }\end{array}$ & .51 & .53 & .52 & .52 & .55 \\
\hline $\begin{array}{l}\text { 16. Seeing people sad at a funeral would make me feel } \\
\text { sad too }\end{array}$ & .55 & .57 & .58 & .58 & .61 \\
\hline $\begin{array}{l}\text { 19. Seeing a man pointing a gun at an unarmed person } \\
\text { would make me feel frightened }\end{array}$ & .50 & .55 & .54 & .54 & .56 \\
\hline $\begin{array}{l}\text { 27. I would feel worried for a small child being chased } \\
\text { by a big dog }\end{array}$ & .54 & .57 & .57 & .57 & .61 \\
\hline \multicolumn{6}{|l|}{ Somatic - Positive } \\
\hline 3. Seeing others laugh makes me laugh too & .51 & .54 & .51 & .51 & .55 \\
\hline $\begin{array}{l}\text { 11. My heart beats faster watching an action- adventure } \\
\text { movie }\end{array}$ & .39 & .38 & .42 & .42 & .38 \\
\hline $\begin{array}{l}\text { 15. Seeing someone enjoying a tasty dessert makes my } \\
\text { mouth water }\end{array}$ & .36 & .37 & .39 & .39 & .37 \\
\hline 20. Seeing people looking cheerful makes me grin & .65 & .68 & .65 & .65 & .70 \\
\hline $\begin{array}{l}\text { 30. When I see children smiling, I smile too } \\
\text { Somatic - Negative }\end{array}$ & .62 & .64 & .62 & .62 & .65 \\
\hline $\begin{array}{l}\text { 4. I would sweat if I saw someone getting their tooth } \\
\text { pulled out }\end{array}$ & .35 & .37 & .38 & .38 & .46 \\
\hline 7. I flinch when I see someone hit & .47 & .51 & .50 & .50 & .59 \\
\hline 14. I would get tears in my eyes if I saw my friend cry & .44 & .46 & .46 & .46 & .47 \\
\hline 24. I cringe when I see someone cut or bleeding & .38 & .42 & .42 & .42 & .54 \\
\hline 29. My heart beats faster when I see a scary TV show & .40 & .42 & .44 & .44 & .52 \\
\hline
\end{tabular}
Note. All factor loadings are significant at 05 . 
Table 2

Model Fit Indices and Comparisons for One, Two, and Three-factor Models and the Two Second-order Factor Models.

\begin{tabular}{|c|c|c|c|c|c|c|c|c|c|c|}
\hline \multicolumn{2}{|c|}{ Model } & \multirow{2}{*}{$\begin{array}{c}\text { Satorra-Bentler } \\
\text { Scaled } \chi^{2}\end{array}$} & \multirow[t]{2}{*}{ df } & \multirow{2}{*}{$\begin{array}{l}\text { Scaling } \\
\text { factor }\end{array}$} & \multirow[t]{2}{*}{$\mathrm{BIC}$} & \multirow[t]{2}{*}{ CFI } & RMSEA & \multirow{2}{*}{$\begin{array}{c}\text { Model } \\
\text { comparison }\end{array}$} & \multirow[t]{2}{*}{$\Delta \mathrm{df}$} & \multirow{2}{*}{$\begin{array}{c}\text { Satorra-Bentler } \\
\text { Scaled } \Delta \chi^{2}\end{array}$} \\
\hline & & & & & & & & & & \\
\hline 1 & One empathy & 7861.26 & 405 & 1.1100 & 280142.36 & .78 & .063 & & & \\
\hline & factor model & & & & & & & & & \\
\hline 2 & Two-factor & 7208.74 & 404 & 1.1085 & 279415.58 & .80 & .060 & 1 vs. 2 & 1 & 428.39 \\
\hline 3 & Three-factor & 6577.13 & 402 & 1.1078 & 278727.55 & .82 & .057 & 1 vs. 3 & 3 & 1024.95 \\
\hline & model & & & & & & & & & \\
\hline 4 & Three $1^{\text {st }}$ order & 6577.13 & 402 & 1.1078 & 278727.55 & .82 & .057 & & & \\
\hline 5 & Six $1^{\text {st }}$ order & 5947.46 & 400 & 1.1068 & 278040.95 & .84 & .054 & 4 vs. 5 & 2 & 637.92 \\
\hline
\end{tabular}

Note. Model 3 and 4 are essentially the same model with different parametrization, hence the same model fit indices. BIC $=$ Bayesian Information Criterion; $\mathrm{df}=$ degree of freedom; CFI = Comparative Fit Index; RMSEA = Root Mean Square Error of Approximation . All incremental $\Delta \chi^{2}$ values in the last column are significant at .001 . 
Table 3

Internal Reliabilities, Descriptive Statistics, Range of Item-total Correlations and Sex Differences in CASES

\begin{tabular}{|c|c|c|c|c|c|c|c|}
\hline \multirow{3}{*}{ CASES scales ${ }^{a}$} & \multicolumn{3}{|c|}{ Full sample } & \multirow{3}{*}{$\begin{array}{l}\text { Female } \\
M(S D)\end{array}$} & \multirow{3}{*}{$\begin{array}{c}\text { Male } \\
M(S D)\end{array}$} & \multicolumn{2}{|c|}{ Sex difference } \\
\hline & Cronbach's & $M(S D)$ & Item-total & & & $t^{b}$ & Cohen's d \\
\hline & Alpha & & correlation & & & & \\
\hline Total (30) & .91 & 32.58 & $.35-.61$ & 35.90 & 30.46 & 15.26 & 0.46 \\
\hline & & $(12.12)$ & & $(11.30)$ & $(12.14)$ & & \\
\hline Positive (15) & .85 & $16.65(6.44)$ & $.35-.62$ & $18.38(6.05)$ & $15.55(6.44)$ & 15.04 & 0.45 \\
\hline Negative (15) & .83 & $15.90(6.53)$ & $.37-.53$ & $17.46(6.16)$ & $14.91(6.56)$ & 13.23 & 0.40 \\
\hline Cognitive (10) & .82 & $10.31(4.37)$ & $.37-.62$ & $11.32(4.11)$ & $9.67(4.40)$ & 12.90 & 0.39 \\
\hline Affective (10) & .80 & $11.93(4.44)$ & $.35-.56$ & $13.19(4.10)$ & $11.14(4.47)$ & 15.91 & 0.48 \\
\hline Somatic (10) & .76 & $9.46(4.22)$ & $.36-.50$ & $11.03(3.95)$ & $8.47(4.10)$ & 21.01 & 0.64 \\
\hline Cognitive - Positive (5) & .66 & $5.30(2.32)$ & $.34-.48$ & $5.94(2.17)$ & $4.91(2.32)$ & 15.11 & 0.46 \\
\hline Cognitive - Negative (5) & .74 & $4.99(2.36)$ & $.42-.58$ & $5.37(2.36)$ & $4.76(2.49)$ & 8.44 & 0.25 \\
\hline Affective-Positive (5) & .69 & $6.02(2.46)$ & $.33-.52$ & $6.48(2.32)$ & $5.74(2.50)$ & 10.25 & 0.31 \\
\hline
\end{tabular}




\begin{tabular}{lccccccc}
\hline Affective - Negative (5) & .70 & $5.90(2.52)$ & $.39-.52$ & $6.71(2.32)$ & $5.40(2.51)$ & 18.02 & 0.54 \\
Somatic-Positive (5) & .64 & $5.49(2.42)$ & $.28-.53$ & $6.19(2.27)$ & $5.04(2.40)$ & 16.18 & 0.49 \\
Somatic-Negative (5) & .64 & $3.98(2.42)$ & $.31-.45$ & $4.83(2.34)$ & $3.44(2.32)$ & 19.62 & 0.60
\end{tabular}

Note. $M=$ mean; $S D=$ standard deviation; CASES = Cognitive, Affective and Somatic Empathy Scales;

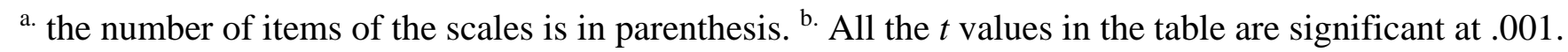


Table 4

Correlations between CASES and Callous-unemotional (CU) Traits, Child Behavior Checklist (CBCL) subscales

\begin{tabular}{|c|c|c|c|c|c|c|}
\hline \multirow{2}{*}{ CASES scales } & & \multirow{2}{*}{$\begin{array}{l}\text { Self-report CU } \\
\qquad(n=2427)\end{array}$} & \multirow{2}{*}{$\begin{array}{l}\text { Parent-report CU } \\
(n=2393 \sim 2507)\end{array}$} & \multicolumn{3}{|c|}{ CBCL $(n=1131 \sim 1149))$} \\
\hline & & & & Rule-breaking & Aggressive & Anxiety/ Depression \\
\hline One-factor & Total & $-.49^{*}$ & $-.14^{*}$ & $-.09^{*}$ & -.05 & .000 \\
\hline \multirow[t]{2}{*}{ Two-factor } & Positive & $-.47^{*}$ & $-.14^{*}$ & $-.10^{*}$ & -.03 & .003 \\
\hline & Negative & $-.44^{*}$ & $-.13^{*}$ & $-.08^{*}$ & -.06 & -.002 \\
\hline \multirow[t]{3}{*}{ Three-factor } & Cognitive & $-.45^{*}$ & $-.13^{*}$ & $-.09^{*}$ & -.06 & -.008 \\
\hline & Affective & $-.45^{*}$ & $-.13^{*}$ & $-.08^{*}$ & -.02 & .016 \\
\hline & Somatic & $-.38^{*}$ & $-.15^{*}$ & $-.06^{*}$ & .00 & .051 \\
\hline \multirow[t]{6}{*}{ Six-factor } & Cognitive - Positive & $-.45^{*}$ & $-.13^{*}$ & $-.10^{*}$ & -.04 & .003 \\
\hline & Cognitive - Negative & $-.37^{*}$ & $-.11^{*}$ & $-.07^{*}$ & $-.06^{*}$ & -.016 \\
\hline & Affective-Positive & $-.38^{*}$ & $-.11^{*}$ & $-.07^{*}$ & .00 & .002 \\
\hline & Affective - Negative & $-.43^{*}$ & $-.12^{*}$ & $-.07^{*}$ & -.03 & .026 \\
\hline & Somatic-Positive & $-.39^{*}$ & $-.15^{*}$ & $-.08^{*}$ & -.02 & .000 \\
\hline & Somatic-Negative & $-.28^{*}$ & $-.11^{*}$ & -.03 & .02 & $.091^{*}$ \\
\hline
\end{tabular}

Note. CASES = Cognitive, Affective and Somatic Empathy Scales; ${ }^{*} p<.05$ 
Table 5

Correlations between CASES and Reactive Aggression (RA)/Proactive Aggression (PA)

$$
\text { Self-report PA RA }(n=4411 \sim 4576) \quad \text { Parent-report PA RA }(n=2347 \sim 2515)
$$

$$
\text { Zero-order Partial Zero-order } \quad \text { Partial }
$$

\begin{tabular}{|c|c|c|c|c|c|c|c|c|c|c|c|}
\hline One-factor & Total & $.05^{*}$ & $-.08^{*}$ & -.02 & $.13^{*}$ & $-.15^{*}$ & $-.05^{*}$ & $-.10^{*}$ & $-.08^{*}$ & -.003 & $-.09^{*}$ \\
\hline \multirow[t]{2}{*}{ Two-factor } & Positive & $.04^{*}$ & $-.08^{*}$ & -.02 & $.11^{*}$ & $-.13^{*}$ & $-.05^{*}$ & $-.09^{*}$ & $-.08^{*}$ & .002 & $-.09^{*}$ \\
\hline & Negative & $.06^{*}$ & $-.08^{*}$ & -.01 & $.13^{*}$ & $-.14^{*}$ & $-.06^{*}$ & $-.09^{*}$ & $-.08^{*}$ & -.009 & $-.08^{*}$ \\
\hline \multirow[t]{3}{*}{ Three-factor } & Cognitive & $.03^{*}$ & $-.06^{*}$ & -.01 & $.09^{*}$ & $-.11^{*}$ & $-.06^{*}$ & $-.09^{*}$ & $-.08^{*}$ & -.012 & $-.08^{*}$ \\
\hline & Affective & $.07^{*}$ & $-.10^{*}$ & -.01 & $.17^{*}$ & $-.19^{*}$ & -.03 & $-.09^{*}$ & $-.06^{*}$ & .014 & $-.09^{*}$ \\
\hline & Somatic & $.11^{*}$ & -.02 & $.05^{* * *}$ & $.17^{*}$ & $-.12^{*}$ & -.02 & $-.08^{*}$ & $-.05^{*}$ & .026 & $-.08^{*}$ \\
\hline \multirow[t]{5}{*}{ Six-factor } & Cognitive - Positive & .01 & $-.08^{*}$ & $-.04^{*}$ & $.08^{*}$ & $-.12^{*}$ & $-.06^{*}$ & $-.09^{*}$ & $-.08^{*}$ & -.009 & $-.08 *$ \\
\hline & Cognitive - Negative & $.05^{*}$ & $-.03^{*}$ & .02 & $.09^{*}$ & $-.08^{*}$ & $-.06^{*}$ & $-.07^{*}$ & $-.07^{*}$ & -.013 & $-.07^{*}$ \\
\hline & Affective-Positive & $.07^{*}$ & $-.05^{*}$ & .02 & $.13^{*}$ & $-.12^{*}$ & -.02 & $-.08^{*}$ & $-.05^{*}$ & .022 & $-.09^{*}$ \\
\hline & Affective - Negative & $.04^{*}$ & $-.13^{*}$ & $-.04^{* *}$ & $.16^{*}$ & $-.21^{*}$ & -.04 & $-.07^{*}$ & $-.06^{* *}$ & .004 & $-.07^{*}$ \\
\hline & Somatic-Positive & $.09^{*}$ & -.02 & $.04^{* *}$ & $.13^{*}$ & $-.10^{*}$ & -.03 & $-.08^{*}$ & $-.06^{*}$ & .007 & $-.08^{*}$ \\
\hline
\end{tabular}

$\begin{array}{lllllllll}\text { CASES scales } & \text { RA } & \text { PA sum score } & \text { RA } & \text { PA } & \text { RA } & \text { PA sum score } & \text { RA } & \text { PA }\end{array}$ 


$\begin{array}{llllllllllll}\text { Somatic-Negative } & .11^{*} & -.02 & .06^{*} & .16^{*} & -.11^{*} & .01 & -.05^{*} & -.02 & .038 & -.06^{*}\end{array}$

Note. CASES = Cognitive, Affective and Somatic Empathy Scales; ${ }^{*} \mathrm{p}<.05$ 
Table 6

Correlation between CASES and Self-report Multidimensional Peer Victimization Scores $(n=4471 \sim 4624)$

\begin{tabular}{|c|c|c|c|c|c|}
\hline \multicolumn{2}{|c|}{ CASES scales } & $\begin{array}{l}\text { Physical } \\
\text { victimization }\end{array}$ & $\begin{array}{l}\text { Social } \\
\text { manipulation }\end{array}$ & $\begin{array}{c}\text { Verbal } \\
\text { victimization }\end{array}$ & $\begin{array}{l}\text { Attack on } \\
\text { property }\end{array}$ \\
\hline One-factor & Total & $-.032^{*}$ & $.032^{*}$ & $.030^{*}$ & .013 \\
\hline \multirow[t]{2}{*}{ Two-factor } & Positive & -.028 & .024 & $.031^{*}$ & .013 \\
\hline & Negative & $-.030^{*}$ & $.036^{*}$ & $.030^{*}$ & .010 \\
\hline Three- & Cognitive & $-.051^{*}$ & .009 & .014 & .005 \\
\hline \multirow[t]{2}{*}{ factor } & Affective & .013 & $.069^{*}$ & $.059^{*}$ & .025 \\
\hline & Somatic & .011 & $.092^{*}$ & $.076^{*}$ & $.056^{*}$ \\
\hline \multirow[t]{6}{*}{ Six-factor } & Cognitive - Positive & $-.056^{*}$ & .003 & .017 & .002 \\
\hline & Cognitive - Negative & $-.036^{*}$ & .015 & .015 & .008 \\
\hline & Affective-Positive & $.033^{*}$ & $.059^{*}$ & $.055^{*}$ & $.034^{*}$ \\
\hline & Affective - Negative & -.009 & $.064^{*}$ & $.052^{*}$ & .010 \\
\hline & Somatic-Positive & -.007 & $.064^{*}$ & $.065^{*}$ & $.036^{*}$ \\
\hline & Somatic-Negative & $.030^{*}$ & $.100^{*}$ & $.072^{*}$ & $.067^{*}$ \\
\hline
\end{tabular}

Note. CASES = Cognitive, Affective and Somatic Empathy Scales; ${ }^{*} \mathrm{p}<.05$ 